\title{
50 copies
}

NATIONAL AERONAUTICS AND SPACE ADMINISTRATION

N68-1.67:3

Technical Report 32-1151

\section{Magnetic Susceptibility of Glassy Carbon}

\author{
D. B. Fischbach
}

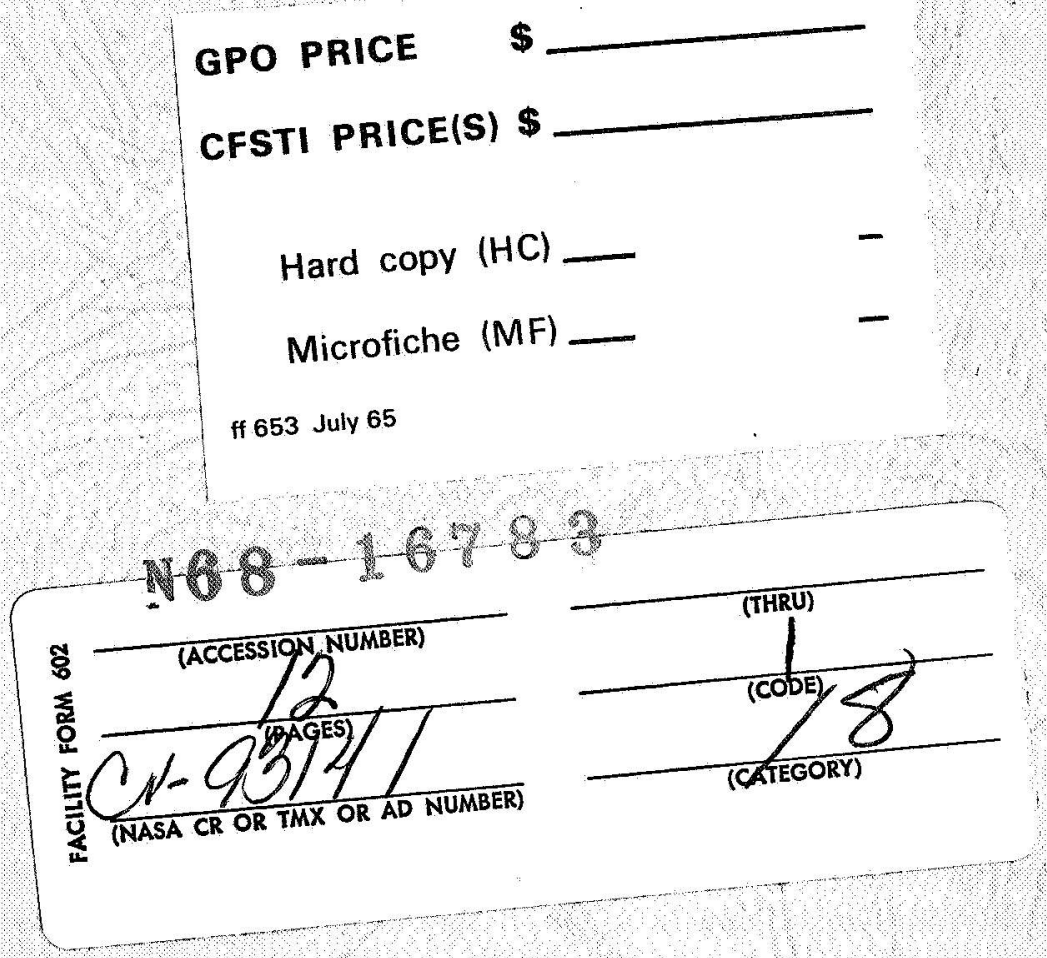

JET PROPULSION LA B O R A TOR Y CALITOR NIA INSTITUTE OF TECHNOLOGY PASADENA, CALIFORNIA

February 1, 1968 


\title{
Technical Report 32-1151
}

\section{Magnetic Susceptibility of Glassy Carbon}

\author{
D. B. Fischbach
}

Approved by:

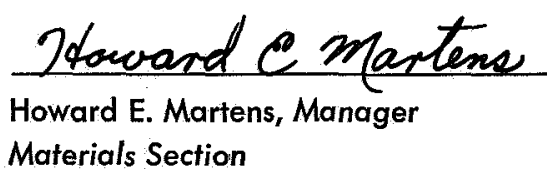

JET PROPULSION LABORATORY CALIFORNIA INSTITUTE OF TECHNOLOGY

PASADENA, CALIFORNIA

February 1, 1968 
TECHNICAL REPORT 32-1151

Copyright (C) 1968

Jet Propulsion Laboratory

California Institute of Technology

Prepared Under Contract No. NAS 7-100

National Aeronautics \& Space Administration 


\title{
PRECEDING PAGE BLANK NOT FILMED.
}

Contents

\begin{abstract}
I. Introduction . . . . . . . . . . . . . . . . . . . . 1
II. Experimental Technique . . . . . . . . . . . . . . . . . . . . 1

III. Results . . . . . . . . . . . . . . . . . . . . 3

IV. Discussion. . . . . . . . . . . . . . . . . . . 4

v. Conclusions ........ . . . . . . . . . . 6

References . . . . . . . . . . . . . . . . . 7
\end{abstract}

\section{Table}

1. Spectrochemical analyses of glassy carbon samples. . . . . . . . 2

\section{Figures}

1. Magnetic susceptibility as a function of reciprocal field strength for representative as-received and heat-treated glassy carbon samples . . . . . 3

2. The influence of heat treatment temperature on total diamagnetic susceptibility, apparent crystallite layer diameter, and interlayer spacing of glassy carbon . . . . . . . . . . . . . . . . . 4

3. The dependence of total diamagnetic susceptibility on apparent crystallite layer diameter . . . . . . . . . . . . . . . . . . . . 5 



\title{
PRECEDING PAGE BLANK NOT FILMED.
}

\begin{abstract}
The magnetic susceptibility of two grades of Japanese glassy carbon has been measured at room temperature as a function of magnetic field strength, heat treatment temperature, and high-temperature tensile deformation. The magnetic behavior was correlated with impurity content and with interlayer spacing and apparent crystallite layer diameter. The structure sensitivity of the diamagnetism of nongraphitizing carbons, such as glassy carbon, is compared with that of graphitizing carbons, and some differences are noted and discussed.
\end{abstract}




\section{Magnetic Susceptibility of Glassy Carbon}

\section{Introduction}

The diamagnetism of carbons is highly structuresensitive. Because of this the magnetic behavior of these materials is of interest as a structure probe as well as in its own right. Although there is a considerable body of literature on the magnetic properties of "soft" graphitizing carbons and polycrystalline and single-crystal graphite, relatively little information appears to be available on "hard" nongraphitizing carbons. Such carbons retain a highly disordered crystallographic structure even after prolonged heat treatment at very high temperatures under normal ambient pressure. This report presents the results of an investigation of the magnetic behavior of Japanese glassy carbon (Refs. 1 and 2), a particular nongraphitizing carbon. The correlation between magnetic susceptibility and microstructure is examined under the influence of high-temperature heat treatment and tensile deformation.

\section{Experimental Technique}

Two grades of glassy carbon, designated GC-20 and GC-30 by the manufacturer, ${ }^{1}$ were examined. Although

"Tokai Electrode Manufacturing Company, Ltd. details of the manufacturing process are not known, these carbons are believed to be produced by the slow and carefully controlled pyrolysis of polymer resins. The result is a hard, vitreous-appearing, impervious carbon with a bulk density of about $1.5 \mathrm{~g} / \mathrm{cm}^{3}$. The GC-20 and GC-30 carbons had been heat-treated at 2000 and $3000^{\circ} \mathrm{C}$, respectively, according to the manufacturer. Both materials were obtained in the form of plates measuring about $10 \times 10 \times 0.3 \mathrm{~cm}$. The results presented were obtained on samples from four plates of each grade, designated $20-1,-2,-3,-4$ and $30-1,-2,-3,-4$. Some tensile and microstructural properties of this same stock have been described elsewhere (Refs. 3 and 4). The results of semiquantitative spectrochemical analyses on several of the plates are given in Table 1.

Magnetic susceptibility and X-ray diffraction samples were taken from the deformed gage and undeformed butt portions of tensile specimens that had been tested to fracture at temperatures ranging from 1600 to $2900^{\circ} \mathrm{C}$. Tensile elongations varied from 1.2 to $5.1 \%$ for GC-30 and from 9 to $24 \%$ for GC-20, which was much more ductile. Some samples taken from as-received stock were heat-treated without deformation. Heat treatments and deformation tests were carried out in graphite tube resistance furnaces in helium or argon at a pressure of 
Table 1. Spectrochemical analyses of glassy carbon samples

\begin{tabular}{|c|c|c|c|c|c|c|c|}
\hline Element & $\begin{array}{c}20-1^{\mathrm{a}} \\
\text { As-received, } \\
\text { part } / 10^{6}\end{array}$ & $\begin{array}{c}20-3^{b} \\
\text { As-received, } \\
\text { part } / 10^{6}\end{array}$ & $\begin{array}{c}20-4^{\mathrm{b}} \\
\text { As-received, } \\
\text { part } / 10^{6}\end{array}$ & $\begin{array}{c}20-4^{b} \\
3000^{\circ} \mathrm{C} \\
\text { part } / 10^{6}\end{array}$ & $\begin{array}{c}30-2^{b} \\
\text { As-received, } \\
\text { part } / 10^{6}\end{array}$ & $\begin{array}{c}20)^{c} \\
\text { part } / 10^{\mathrm{g}}\end{array}$ & $\begin{array}{c}305^{\mathrm{e}} \\
\text { part } / 10^{\mathrm{s}}\end{array}$ \\
\hline $\begin{array}{l}\mathrm{Si} \\
\mathrm{Al} \\
\mathrm{Fe} \\
\mathrm{Ti} \\
\mathrm{Cu} \\
\mathrm{Mn} \\
\mathrm{Ca} \\
\mathrm{Mg} \\
\mathrm{B} \\
\mathrm{Ba} \\
\mathrm{Na} \\
\mathrm{K} \\
\mathrm{Ni} \\
\mathrm{Cr} \\
\mathrm{V} \\
\mathrm{Co}\end{array}$ & $\begin{array}{r}89 \\
<20 \\
5.8 \\
20 \\
13\end{array}$ & $\begin{array}{c}5-15 \\
20-40 \\
20-40 \\
10-20 \\
<5 \\
<1 \mathrm{ND} \\
300-700 \\
<1 \\
<5 \mathrm{ND} \\
15-30 \\
3-10 \\
15-30 \\
<5 \mathrm{ND} \\
<5 \mathrm{ND} \\
<5 \mathrm{ND} \\
<5 \mathrm{ND} \\
\mathrm{Zr}, \mathrm{Ag}, \mathrm{Li}, \mathrm{Sr}, \mathrm{A}\end{array}$ & $\begin{array}{c}20-60 \\
20-40 \\
50-100 \\
5-15 \\
<5 \\
<1 \mathrm{ND} \\
100-300 \\
1-5 \\
<5 \mathrm{ND} \\
25-75 \\
15-20 \\
15-30 \\
<5 \mathrm{ND} \\
<5 \mathrm{ND} \\
<5 \mathrm{ND} \\
<5 \mathrm{ND} \\
\mathrm{W}, \mathrm{Zn}, \mathrm{Cb}, \mathrm{C}\end{array}$ & $\begin{array}{rl} & 5-15 \\
< & 5 \mathrm{ND} \\
<5 & 5 \\
< & 5 \\
< & 5 \mathrm{ND} \\
< & 1 \mathrm{ND} \\
& 20-50 \\
< & 1 \\
10-20 \\
<10 \\
3-10 \\
<10 \mathrm{ND} \\
<5 \text { ND } \\
<5 \text { ND } \\
<5 \text { ND } \\
<5 \text { ND } \\
\text { Mo, Pb, Sn }\end{array}$ & $\begin{aligned} & 50-100 \\
& 5-15 \\
&< 5 \\
&<5 \text { ND } \\
&<5 \\
&<1 ~ N D \\
&<5 ~ N D ~ \\
&<1 \\
&<5 \text { ND } \\
&<10 \\
& 3-10 \\
&<10 \text { ND } \\
&<5 \text { ND } \\
&<5 \text { ND } \\
&<5 \text { ND } \\
&<5 \text { ND } \\
& \text { (not detected) }\end{aligned}$ & $\begin{array}{c}27.3 \\
24.7 \\
100 \\
\\
10 \\
10.2 \\
7.2 \\
5.5 \\
1.0\end{array}$ & $\begin{array}{r}1.8 \\
15.2 \\
2.1 \\
\\
0.1 \\
\text { ND } \\
\text { ND } \\
0.6 \\
0.08\end{array}$ \\
\hline $\begin{array}{l}\text { aPacif } \\
\text { bNatic } \\
\text { 'Refer }\end{array}$ & $\begin{array}{l}\text { chemical Lak } \\
\text { trographic La } \\
O S \text { is a speci }\end{array}$ & $\begin{array}{l}\text { ies, Inc. } \\
\text { rified grade of }\end{array}$ & irbon. & & & & \\
\hline
\end{tabular}

about 1 atm. Temperatures were measured with calibrated disappearing-filament optical pyrometers and corrected for window absorption. Because of thermal gradients in the tensile test apparatus, the treatment temperatures of the undeformed butt samples were 50 to $100^{\circ} \mathrm{C}$ lower than those of the deformed gage section samples. Time at temperature varied from 20 to $60 \mathrm{~min}$.

The magnetic susceptibility was measured at room temperature by the Faraday method using a single pan semimicroanalytical balance and a 4-in. electromagnet with "constant force" pole tips (see Ref. 5). Calibrations by an absolute technique using a precision gaussmeter and a comparison technique using high-purity silver were in good agreement. The mass susceptibility $\chi_{i}$ was determined for each of three mutually perpendicular orientations ( $i=1,2,3$ parallel to the length, width, and thickness of the plate) relative to the magnetic field on samples approximately $3 \times 3 \times 3 \mathrm{~mm}$. One of the measured directions of gage section samples was parallel to the tensile axis. The total susceptibility, which is inde- pendent of anisotropy, is defined as

$$
\chi_{T}=\sum_{i=1}^{3} \chi_{i}
$$

The susceptibility anisotropy was measured by the ratio of the maximum $\chi_{i}$ to the minimum $\chi_{i}$. Field strength dependence was determined over the range of approximately 6 to $16 \mathrm{kG}$. The absolute accuracy of the measured $\chi_{i}$ values was estimated to be $3 \%$, but the relative precision of individual measurements was somewhat higher.

Standard Debye-Scherrer powder X-ray diffraction techniques using $\mathrm{Cu} \mathrm{K} \alpha$ radiation were used to determine the interlayer spacing $d$ and the apparent crystallite layer diameter $L_{a}$. The diffraction pattern of diamond, superimposed on the glassy carbon pattern by a separate exposure, was used to correct for film dimension changes in processing. The films were read visually. The glassy 
carbon diffraction pattern was similar to that of other highly disordered carbons with broad peaks at the (002), (10), (004), (11), and sometimes (20) and (12) positions. The interlayer spacing was determined from the position of the (004) peak except for GC-20 samples in the asreceived condition, or heat-treated at temperatures below about $2200^{\circ} \mathrm{C}$. For these samples it was necessary to use the (002) peak because the (004) peak was too weak and broad for accurate reading. The apparent crystallite layer diameter was calculated from the displacement of the (11) peak from the graphite position using the formula of Warren (Ref. 6). Similar $L_{a}$ values were obtained from the (10) peak when the (111) peak of the superimposed diamond pattern did not interfere.

\section{Results}

The magnetic susceptibility of GC-30 samples and heat-treated GC-20 samples was diamagnetic and independent of magnetic field strength. However, the susceptibility of as-received GC-20 became more diamagnetic with increasing field strength. In general, this effect was very small, but it was quite pronounced in plate 20-4. The measured susceptibilities of as-received samples of 20-4 were paramagnetic. Reference to Table 1 suggests that this behavior is due to iron impurity in the GC-20. Using the standard Honda-Owen technique (Ref. 7) to correct for saturable ferromagnetic impurity, good linear plots of susceptibility as a function of reciprocal field strength were obtained, as illustrated in Fig. 1 . The susceptibility of 20-4 extrapolated at infinite field strength to a diamagnetic value in good agreement with those of the other GC-20 plates, which showed only a slight field strength dependence. On the assumption that iron was the only ferromagnetic impurity present, iron contents of 240 part $/ 10^{8}$ in as-received $20-4,9$ part $/ 10^{6}$ in as-received 20-2, and 0 in GC-30 and in GC-20 samples heat-treated at $2600^{\circ} \mathrm{C}$ or above were calculated from the susceptibility data. These results are in reasonable agreement with the semiquantitative analysis values in Table 1 . With the exception of $20-4$, the extrapolated susceptibility differed little from the value determined at the normal measurement field strength of $11 \mathrm{kG}$. For example, the 20-2 extrapolated $\chi_{T}$ value was $-9.3 \times 10^{-6} \mathrm{emu} / \mathrm{g}$ compared with the normal single measurement value of $-8.9 \times 10^{-6} \mathrm{emu} / \mathrm{g}$. This difference is less than the variation in samples from different plates of GC-30 which had no detectable Fe impurity. Therefore, HondaOwen extrapolations were not made for most of the samples.

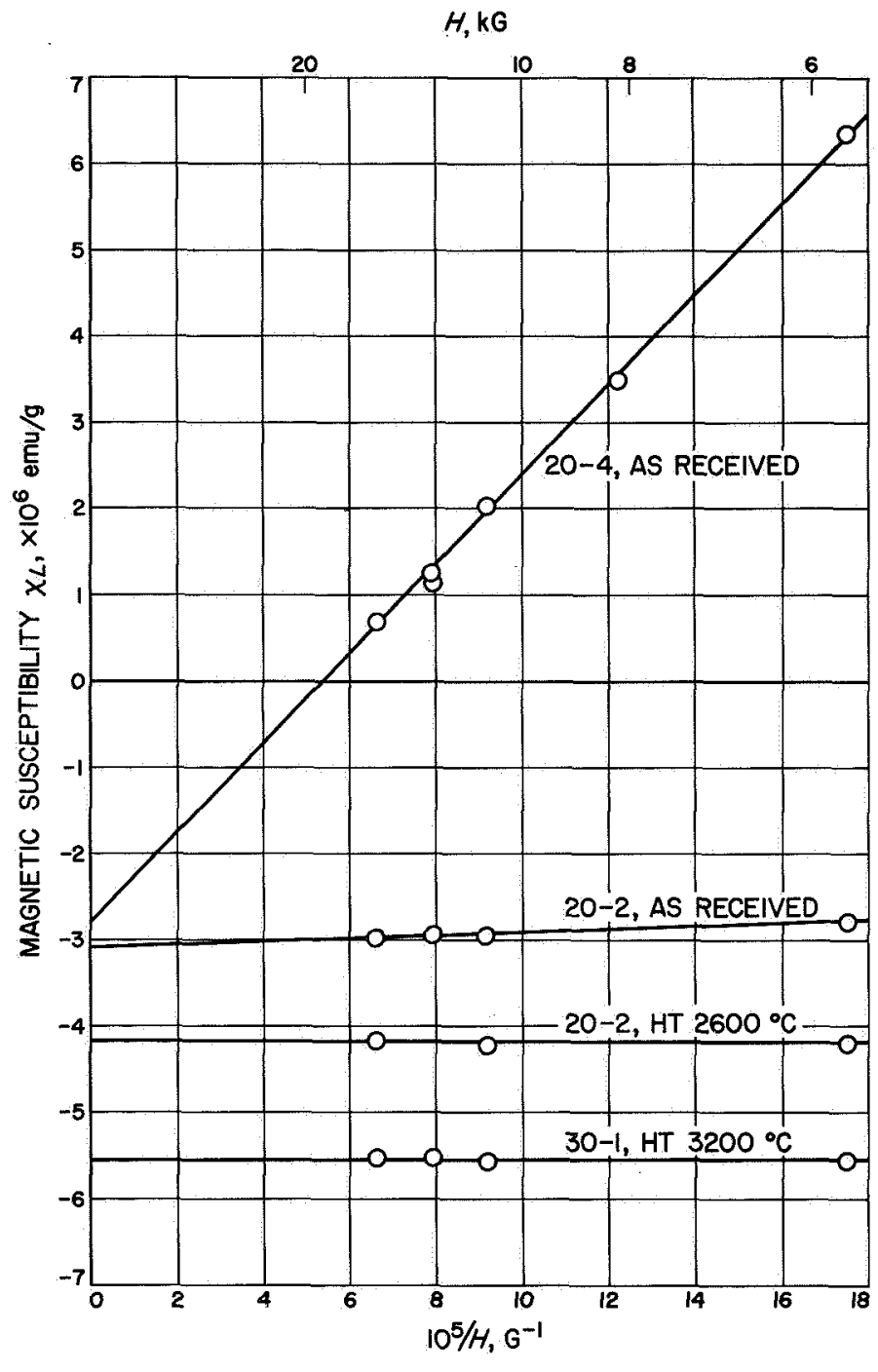

Fig. 1. Magnetic susceptibility as a function of reciprocal field strength for represenfative as-received and heat-treared glassy carbon samples

The influence of heat-treatment temperature and tensile deformation on the total diamagnetic susceptibility, apparent crystallite layer diameter and interlayer spacing is shown in Fig. 2. The open and solid points correspond to GC-20 and GC-30, respectively. The squares indicate as-received values, the circles indicate heattreated samples, and the triangles indicate tensiledeformed gage section samples. The horizontal bars indicate the estimated uncertainty in the treatment temperatures of samples taken from the butt portions of tensile specimens. As expected, treatment at temperatures in the range 1500 to $3000^{\circ} \mathrm{C}$ had no effect on GC-30 which had already been heated to $3000^{\circ} \mathrm{C}$. However, heat treatment caused progressive changes in the 


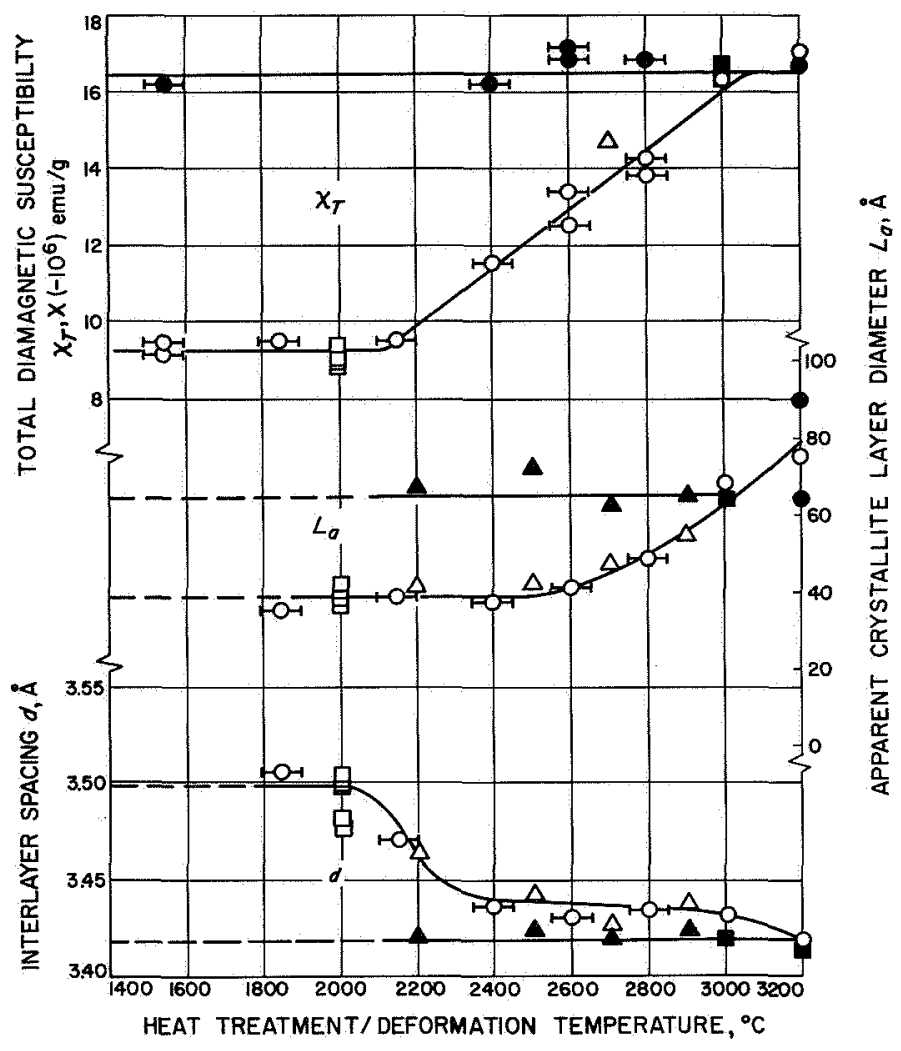

Fig. 2. The influence of heat treatment temperature on total diamagnetic susceptibility, apparent crystallite layer diameter, and interlayer spacing of glassy carbon Solid points, GC-30; open points, GC-20; squares, as-received; circles, heat-freated; triangles, tensile-deformed.

susceptibility and structure of GC-20 until values characteristic of GC-30 were attained after treatment at 3000 to $3200^{\circ} \mathrm{C}$. Changes in $\chi_{r}$ and $d$ began as soon as the treatment temperature exceeded the previous maximum of $2000^{\circ} \mathrm{C}$, but no $L_{a}$ increase occurred until the treatment temperature exceeded $2600^{\circ} \mathrm{C}$. The interlayer spacing decreased in two stages, with the major change occurring in the 2000 to $2400^{\circ} \mathrm{C}$ range in which $L_{a}$ remained constant. Even after a 1 -h treatment at $3200^{\circ} \mathrm{C}$ the $L_{a}$ and $d$ values of glassy carbon were characteristic of an ungraphitized, turbostratic carbon. These results of the effect of heat treatment on X-ray structure are similar to those reported by others (Refs. 2 and 8 ).

The triangle points in Fig. 2 indicate tensile-deformed gage section samples. Deformation had very little effect on either $L_{a}$ or $d$. Insufficient susceptibility data was obtained on deformed samples to determine whether there was a real effect on $\chi_{T}$. However, tensile deformation caused a pronounced change in the susceptibility anisotropy. Undeformed GC-20 samples had anisotropy ratios of 1.00 to 1.04 , while GC-30 samples had ratios of 1.02 to 1.06. However, a GC-20 sample elongated $24 \%$ had an anisotropy ratio of 1.82 , while a sample from a different lot, elongated about $15 \%$, had a ratio of 1.5 . In each case, the low susceptibility direction was parallel to the tensile axis. Thus, large tensile deformation introduces a pronounced anisotropy in the initially nearly isotropic material.

\section{Discussion}

The diamagnetic susceptibility of pure graphite and disordered graphitic carbons consists of two components: (1) a small contribution from the ion cores that is isotropic and contributes about $-1 \times 10^{-6} \mathrm{emu} / \mathrm{g}$ to the total susceptibility and (2) a conduction electron contribution that is highly anisotropic and accounts for the balance of the total susceptibility. Measurements with the magnetic field parallel to the layer planes determine only the core susceptibility. Measurements normal to the layer planes determine the sum of the core and conduction electron components. The conduction electron susceptibility depends upon both the interlayer spacing and the apparent crystallite layer diameter. This structure sensitivity results from the influence of microstructure on the Fermi level and the detailed electronic band structure. The diamagnetism of nongraphitizing carbons would also be expected to be structure-sensitive, but differences in magnetic behavior may result from differences in the detailed structure.

The structure of glassy carbon, and indeed of nongraphitizing carbons in general, is not well understood. It appears to be distinguished from the structure of graphitizing carbons primarily by the presence of appreciable nontrigonal (nongraphitic) bonding. A reasonable but crude model of glassy carbon consists of small crystallites made up of roughly parallel stacks of graphitelike layers with very little layer stacking order and appreciable lattice distortion. The distortion results from extensive nontrigonal crosslink bonding between and perhaps within the crystallites, connecting them in a randomly oriented array. Bonding between the layer plane edges of crystallites would be expected to be stronger than bonding between layer plane faces or between faces and edges. With a macroscopically random crystallite orientation texture, this could have the effect of creating tangled chains of crystallites reminiscent in many ways of the structure of uncrystallized long chain polymers. This simple model is generally consistent with the results of X-ray diffraction studies (Refs. 2 
and 8), the mechanical behavior (Refs. 3 and 4), and the nongraphitizability of glassy carbon. The magnetic behavior is also consistent with a model of this type. Qualitatively, the magnetic susceptibility of glassy carbons is very similar in magnitude and heat treatment response to that of turbostratic graphitizing carbons and carbon blacks with small $L_{a}$ (see Refs. 9-11). However, there are some interesting quantitative differences.

It is well established that the total diamagnetic susceptibility of graphitizing carbons increases rapidly with increasing apparent crystallite diameter $L_{a}$ (see Refs. 911). A strong $L_{a}$ dependence is also found in nongraphitizing carbons, as shown in Fig. 3. The present results on glassy carbon fit very nicely with results obtained by Adamson and Blayden (Ref. 10) on a nongraphitizing cellulose carbon. However, for both of these nongraphitizing carbons the susceptibility increases much more rapidly with $L_{a}$ than in the case for graphitizing carbons. The behavior of pyrolytic carbon (Ref. 11) with $d \simeq 3.43 \mathrm{~A}$ is shown by the dotted line in Fig. 3. The GC-30 value of $-16.5 \times 10^{-6} \mathrm{emu} / \mathrm{g}$ corresponds to an $L_{a}$ value of about $130 \mathrm{~A}$ in pyrolytic carbon. This is twice the $L_{a}$ value measured here for GC-30. This behavior could be interpreted in terms of a narrow distribution of crystallite sizes in nongraphitizing carbons and a very broad size distribution in graphitizing carbons, ${ }^{2}$ but there seems to be little direct evidence for such a difference in size distribution. Alternatively, the significance of $L_{a}$

${ }^{2}$ Private communication from A. Pacault.

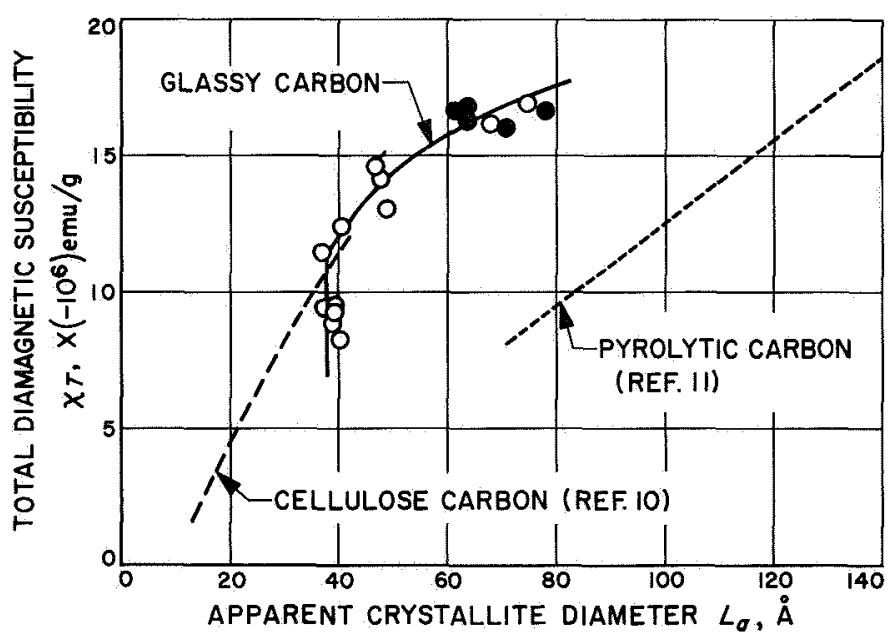

Fig. 3. The dependence of total diamagnetic susceptibility on apparent crystallite layer diameter Solid points, GC-30; open points, GC-20. may differ in these two classes of carbon. Severe lattice distortion associated with crosslink bonding may result in serious underestimation of the crystallite size in nongraphitizing carbons. It is well known that it is very difficult to separate distortion broadening from crystallite size broadening in the usual diffraction line broadening technique for carbon crystallite size measurement (Ref. 12). ${ }^{3}$ Warren's peak displacement method also assumes no lattice distortion within the layer planes. In fact, it can be argued that $L_{a}(h k)$ is actually an inverse measure of the extent of the $(h k)$ scattering volume in the reciprocal lattice, and is therefore more a measure of lattice distortion such as layer plane bending, etc., than of true crystallite size (Ref. 12). That is why $L_{a}$ has been termed the apparent crystallite layer diameter in this report.

The presence of extensive crosslink bonding and lattice distortion would also be expected to affect $\chi_{T}$ directly. However, it is difficult to separate unambiguously such effects, if they exist, from the influences of other structural parameters such as layer stacking disorder, true crystallite size, impurities, etc. In the heat treatment temperature range 2200 to $2600^{\circ} \mathrm{C}$ the diamagnetism of GC-20 increases without any accompanying change in $L_{a}$, as shown in both Figs. 2 and 3. This may be attributed primarily to the associated reduction in impurity content by volatilization (see Table 1). Although extrapolation of the susceptibility to infinite field corrects for saturable ferromagnetic contributions, it does not correct for paramagnetic contributions from impurity ions or trapped electrons. Impurities may also affect the diamagnetic susceptibility by changing the Fermi level. Comparison of the chemical analysis results in Table 1 for asreceived 20-1 and 20-3 with as-received 30-2, and of as-received with heat-treated $20-4$, shows that heating to $3000^{\circ} \mathrm{C}$ results in an appreciable decrease in the content of all the impurities detected with the possible exception of Si and $\mathrm{B}$. Although chemical analysis data are available only for the $3000^{\circ} \mathrm{C}$ treatment, impurity volatilization would be expected to proceed continuously with increasing treatment temperature above the previous maximum of $2000^{\circ} \mathrm{C}$. The susceptibility field strength dependence results show that the iron is all lost at temperatures of $2600^{\circ} \mathrm{C}$ or below and the effect of heat treatment on total susceptibility suggests that most of the purification is accomplished in this range. The major impurities detected were $\mathrm{Ca}, \mathrm{Ba}, \mathrm{Al}, \mathrm{Fe}, \mathrm{Ti}, \mathrm{K}$, and $\mathrm{Si}$, all of which would be expected to enter a graphitic lattice interstitially and be electron donors.

${ }^{3}$ Also, private communication from W. Ruland. 
The diamagnetism of graphitizing carbons decreases with decreasing interlayer spacing at constant $L_{a}$ as a result of the associated increase in layer stacking order (Refs. 5, 11, 13, and 14). ${ }^{4}$ It is not clear if decreasing interlayer spacing has any effect on $\chi_{T}$ in glassy carbon. No $\chi_{T}$ change was associated with the initial decrease in $d$ resulting from the $2200^{\circ} \mathrm{C}$ heat treatment of GC-20, and the susceptibility increased monotonically with treatment at higher temperatures while $d$ continued to decrease. The concurrent change in impurity content may mask the dependence on interlayer spacing. It is also possible that the influence of interlayer spacing on $\chi_{T}$ in the highly distorted glassy carbon structure differs from that in the more graphitic pyrolytic carbons in which the $d$ dependence has been most clearly observed. In particular, the interlayer spacing decrease in glassy carbon may result more from changes in lattice distortion than from any increase in layer ordering. Even after the $3200^{\circ} \mathrm{C}$ heat treatment the X-ray diffraction results indicate that there is very little layer stacking order in glassy carbon.

The deformation-induced anisotropy of glassy carbon is similar to effects observed in coke-pitch and pyrolytic carbons. It implies a reorientation of crystallite basal planes parallel to the tensile axis. The effect in glassy carbons is surprisingly pronounced, especially in view of the isotropy of the undeformed material. The induced anisotropy is appreciably larger than that which occurs in conventional coke-pitch graphite with a definite initial preferred orientation texture, but it is much smaller than in well-oriented pyrolytic carbons (Ref. 15). The anisotropy ratio of a sample of GC-20 increased from 1.01 to 1.82 as a result of $24 \%$ elongation as noted in Results (Sec. III). For a molded coke-pitch graphite elongated $30 \%$ parallel to the grain the increase was from 1.20 to 1.45 , while $45 \%$ elongation of a similar graphite perpendicular to the grain caused an increase from 0.82 to $1.34 .^{5}$ On the other hand, the anisotropy ratio of pyro-

\footnotetext{
${ }^{4}$ Also, private communication from J. W. McClure.

${ }^{5}$ For the measurement of tensile deformation effects, the anisotropy ratio is defined as the ratio of the maximum susceptibility measured perpendicular to the tensile axis to the susceptibility measured parallel to the axis. In molded graphite deformed parallel to the grain, the layer planes tend to lie parallel to the stress axis so the ratio is greater than 1 ; in the perpendicular to grain orientation, the planes tend to be perpendicular to the tensile axis initially and the ratio is less than 1.
}

lytic carbon stressed parallel to the substrate generally increases from an initial value of 8 to 10 to a value of 40 or larger as a result of 10 to $25 \%$ elongation. These differences appear to be due largely to differences in deformation mechanism. Coke-pitch graphite shows little reduction in area, and most of the observed elongation results from opening cracks; there is relatively little true plastic deformation and the anisotropy increase probably results from grain reorientation. In pyrolytic carbons, because of the pronounced initial orientation texture (layer planes parallel to the substrate in a wrinkled-sheet structure), the initial deformation mechanism is layer plane straightening at essentially constant volume. This results in a very strong uniaxial orientation texture after deformation (Ref. 16). Glassy carbon develops about $80 \%$ of the constant volume reduction in area in tension so that most of the elongation results from true plastic deformation of the material, but little is known about the deformation mechanism. If the structure involves tangled chains of crystallites linked edge to edge as suggested earlier in this discussion, tensile deformation would tend to align the chains parallel to the stress axis. This would produce the observed anisotropy. This hypothesis is consistent with the mechanical properties of glassy carbon such as high tensile strength and high Young's modulus. However, since there is little direct evidence for such a chain structure, this suggestion is largely speculative at this time.

\section{Conclusions}

The diamagnetic behavior of glassy carbon, a nongraphitizing carbon, is similar to that of various graphitizing carbons. However, there are significant differences in the structure sensitivity that appear to be characteristic of nongraphitizing carbons. In particular, differences in the dependence of the diamagnetic susceptibility on apparent crystallite layer diameter, $L_{a}$, suggest that $L_{a}$ may have a different quantitative significance in graphitizing and nongraphitizing carbons. The macroscopic susceptibility anisotropy induced by tensile deformation also appears to be stronger in glassy carbon than in other nearly isotropic carbons and graphites. A more detailed understanding of the structure of glassy carbon will be required before such aspects of the magnetic behavior can be satisfactorily explained. 


\section{References}

1. Yamada, S., and Sato, H., "Some Physical Properties of Glassy Carbon," Nature, Vol. 193, p. 261, 1962.

2. Yamada, S., Sato, H., and Ishii, T., "Eigenschaften und Verwendung von glasantigen Kahlenstaff," Carbon, Vol. 2, p. 253, 1964.

3. Kotlensky, W. V., and Martens, H. E., "Tensile Properties of Glassy Carbon to $2900^{\circ} \mathrm{C}$," Nature, Vol. 206, p. 1246 , 1965. Also available as Paper V-2, Symposium on Carbon, Tokyo, Japan, July 1964.

4. Kotlensky, W. V., and Fischbach, D. B., Tensile and Structural Properties of Glassy Carbon, Technical Report 32-842. Jet Propulsion Laboratory, Pasadena, Calif., Nov. 15, 1965.

5. Fischbach, D. B., "The Magnetic Susceptibility of Pyrolytic Carbons," Proceedings of the 5th Carbon Conference, Vol. 2, p. 27. Pergamon Press, London, 1963.

6. Warren, D. E., "X-ray Diffraction in Random Layer Lattices," Phys. Rev., Vol. 59, p. 693, 1941.

7. Bates, L. F., Modern Magnetism, 4th Ed., p. 134. Cambridge University Press, 1961.

8. Noda, T., and Inagaki, M., "The Structure of Glassy Carbon," Bull. Chem. Soc. Japan, Vol. 37, p. 1534, 1964. Also available as Paper III-10, Symposium on Carbon, Tokyo, Japan, July 1964.

9. Pinnick, H. T., "Magnetic Susceptibility of Carbons and Polycrystalline Graphite. I.," Phys. Rev., Vol. 94, p. 319, 1954.

10. Adamson, A. F., and Blayden, H. E., "Magnetic Studies on Graphites and Mesomorphous Carbons," Proceedings of the 3rd Carbon Conference, p. 147. Pergamon Press, London, 1959.

11. Fischbach, D. B., "On the Structure-Sensitivity of the Diamagnetism of Pyrolytic Carbons," Paper 77, 7th Conference on Carbon, Cleveland, O., June 1965.

12. Mering, J., and Maire, J., "Aspects Structuraux de la Graphitation," in Le Carbones, Vol. I, p. 162. Masson et Cie, Paris, 1965.

13. Fischbach, D. B., "Diamagnetic Susceptibility of Pyrolytic Graphite," Phys. Rev., Vol. 123, p. 1613, 1961.

14. MoClure, J. W., "Diamagnetism of Graphite," Phys. Rev., Vol. 104, p. 666, 1956.

15. Fischbach, D. B., "Effect of Plastic Deformation on Preferred Orientation of Synthetic Carbons," Space Programs Summary 37-27, Vol. IV, pp. 29-31. Jet Propulsion Laboratory, Pasadena, Calif., June 30, 1964.

16. Fischbach, D. B., and Kotlensky, W. V., "On the Mechanisms of High Temperature Plastic Deformation in Pyrolytic Carbons," Electrochem. Tech., Vol. 5, p. 45, 1967. 